\title{
Isopachys borealis Lang \& Böhme, 1990 (Squamata: Scincidae): New distribution record and map
}

\author{
Yodchaiy Chuaynkern $^{1 *}$, Prateep Duengkae ${ }^{2,3}$, Chantip Chuaynkern ${ }^{1}$, and Watchara Chitchamnong ${ }^{2}$ \\ 1 Department of Biology, Faculty of Science, Khon Kaen University, Muaeng, Khon Kaen, 40002 Thailand \\ 2 Department of Forest Biology, Faculty of Forestry, Kasetsart University, Chatuchak, Bangkok, 10900 Thailand \\ 3 Center for Advanced Studies in Tropical Natural Resources, Kasetsart University, Chatuchak, Bangkok, 10900 Thailand \\ * Corresponding author. E-mail: yodchaiy@kku.ac.th
}

\begin{abstract}
We present a new locality for Isopachys borealis Lang \& Böhme, 1990 based on a specimen collected from Salak Phra Wildlife Sanctuary, Kanchanaburi province, western Thailand. The present work represents a new provincial record for Kanchanaburi province. The geographical distribution of the species is reviewed and an updated distribution map is presented.
\end{abstract}

Key words: Reptilia; Scincidae; specimen; first provincial record; Thailand

Isopachys borealis was described as a new species by Lang and Böhme (1990) based on a series of 29 specimens collected from Thailand and Myanmar (holotype: ZFMK 45709 from Lan-Sak, Uthai Thani province, western Thailand). The English common name for $I$. borealis differs among the users and is variously called "Western Legless Skink" (Nabhitabhata et al. 2004; Nabhitabhata and Chan-ard 2005), "Northern Limbless Skink" (Das 2010; Tantipisanuh and Gale 2013) and "Lang's Isopachys" (Uetz and Hošek 2014). Considering the appearance of new specimens in scientific publications, only one additional specimen was referred to in the work of Kunya et al. (2011). This work reported an additional locality of $I$. roulei in Nakhon Ratchasima province (northeastern Thailand) based on a single additional specimen (THNHM 15362). Kunya et al. (2011: 90) also listed as part of their specimens examined one specimen of I. borealis (THNHM 15366, collected from Lansak district, Uthai Thani province by staff of Khao Nang Ram Wildlife Research Station, without collection date). This specimen was not cited elsewhere, and to date, other works about reptiles have not referred to additional specimens (e.g., Chan-ard et al. 1999; Nabhitabhata et al. 2004; Nabhitabhata and Chan-ard 2005; Das 2010; Chuaynkern and Chuaynkern 2012). Therefore, I. borealis is a rare, little-known species of skink.

We recently had the opportunity to examine a single specimen of a limbless lygosomine skink clearly belonging to the genus Isopachys. The specimen (Figures 1 and 2) was collected from Salak Phra Wildlife Sanctuary, Kanchanaburi province (western Thailand) by Watchara Chitchamnong on 6 July 2012. The skink was caught at the front of the Huay Sadong Protected Unit at the coordinates UTM zone 47052277 E /

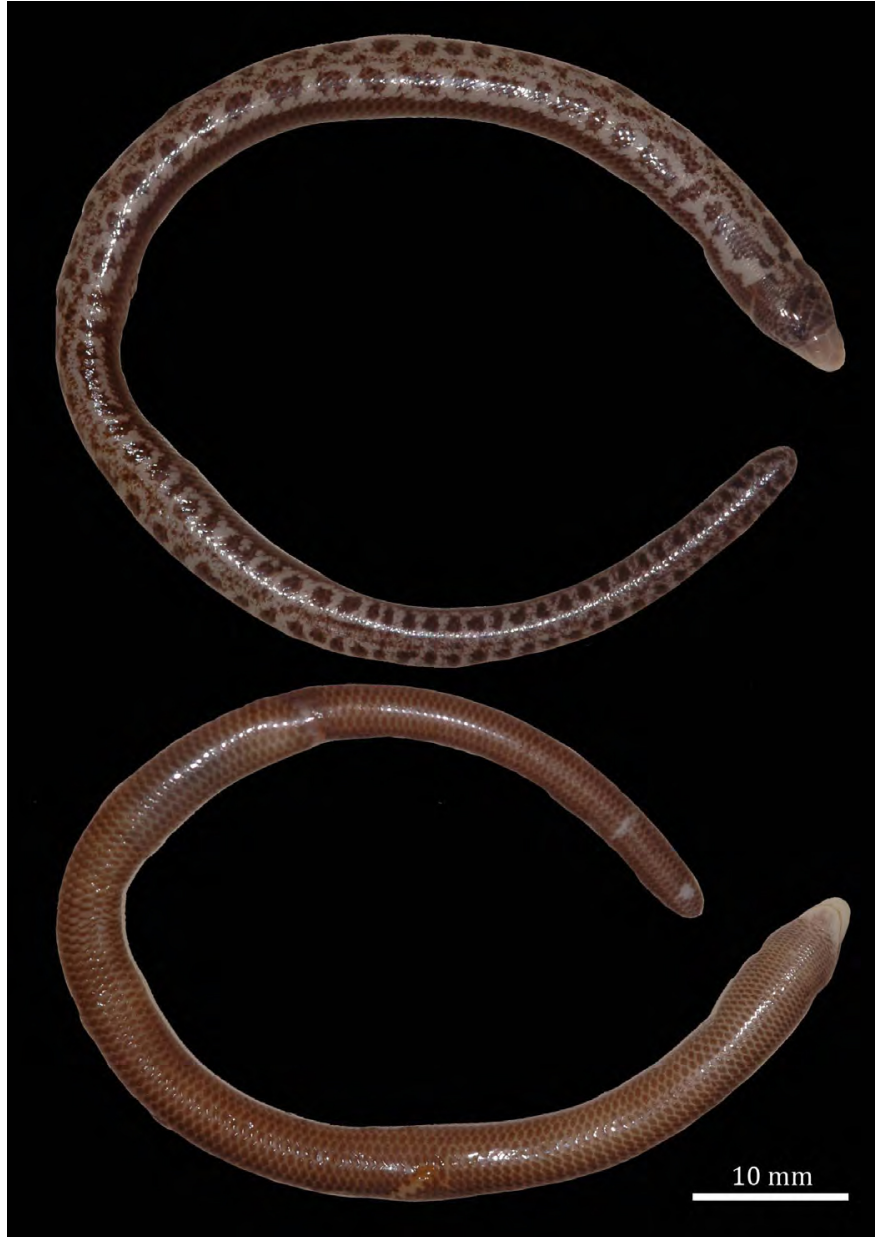

FIGURE 1. Dorsal (A) and ventral (B) views of Isopachys borealis (KKUC 00627; SVL 91.3 mm, TaiL 31.7 mm) from Salak Phra Wildlife Sanctuary, Kanchanaburi province, western Thailand.

$158287 \mathrm{~N}$. Then the skink was fixed in 10\% formalin and transferred to $70 \%$ alcohol. The specimen was catalogued (KKUC oo627) and is housed in the Khon Kaen University Vertebrate Collection (KKUC), Khon Kaen province, Thailand.

Identification of the specimen was based on taxonomic works (Smith 1935; Taylor 1963; Lang and Böhme 1990; Das 


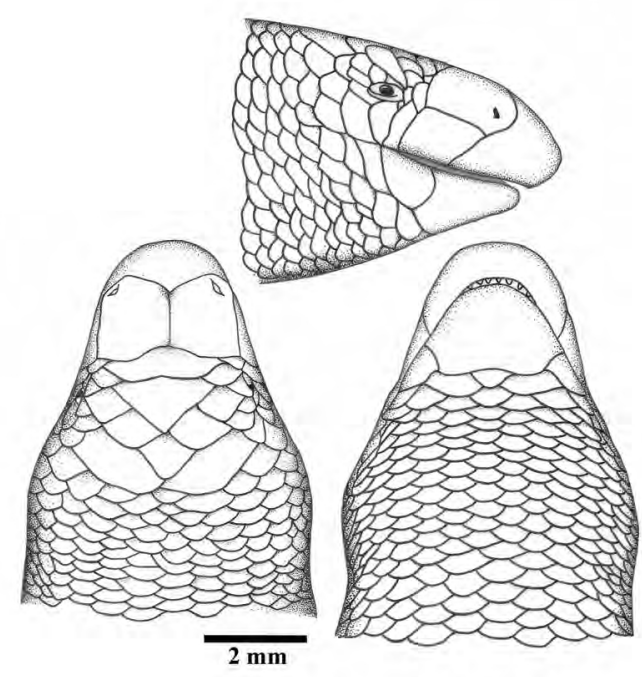

Figure 2. Lateral (above), dorsal (bottom left), and ventral (bottom right) head views of Isopachys borealis (KKUC 00627) from Salak Phra Wildlife Sanctuary, Kanchanaburi province, western Thailand.

2010). The specimen was assigned to Isopachys borealis as it fits the description of the species provided by Lang and Böhme (1990). In the description of I. borealis provided by Das (2010: 234), the nasals were noted as separated but in our specimen there was clearly broad contact as similar to the description of the species and head illustration of the holotype presented by Lang and Böhme (1990). Other morphological characters (Figures 1 and 2) are similar to I. borealis as follows: snout-vent length (SVL) $91.3 \mathrm{~mm}$, tail length (TaiL) $31.7 \mathrm{~mm}$; body elongated; limbless; snout flattened anteriorly; nasals in broad contact; frontonasal larger than frontal; supralabials 5; parietal eye absent; midbody scale rows 18; dorsum pinkish-fawn; forehead darker with T-shaped lighter frontal and frontonasal region; tail-tip rounded; 2 broad dark stripes from parietals, narrowing on dorsum and separated from each other by 2 entire scales and 2 half scales; on tail, dorsal line less distinct and fragmented; venter gray. However, the specimen from Kanchanaburi province shows little differentiation from the type series (in parenthesis): SVL $91.3 \mathrm{~mm}$ (77-177 mm), scale rows at neck 27 (23-28 rows), scale rows at mid body 21 (20-22 rows), scale rows at base of tail 20 (14-17 rows) and scales between parietal and vent 143 (140-152 scales).

The present work documents the first provincial record of Isopachys borealis for Kanchanaburi province, western Thailand, based on a single specimen (KKUC o0627). The locality known as "Huay Sadong Protected Unit, Salak Phra Wildlife Sanctuary" is located ca. $260 \mathrm{~km}$ south of other known localities of the species (Figure 1 ).

To date, the genus Isopachys contains four species: I. anguinoides (Boulenger, 1914), I. borealis Lang \& Böhme, 1990, I. gyldenstolpei Lönnberg, 1916, and I. roulei (Angel, 1920). Among them, I. borealis, I. gyldenstolpei and I. roulei are extremely rare in the natural history collection. Their distribution is quite limited as well (Chuaynkern and Chuaynkern 2012): I. borealis is known from the provinces of Khon Kaen, Tak, Nakhon Sawan, Phetchabun and Uthai Thani provinces; I. gyldenstolpei from Kanchanaburi, Phetchaburi, Prachuap Khiri Khan, Uthai Thani; and I. roulei from Chon Buri and Nakhon Ratchasima provinces. Isopachys Anguinoides, in particular, is likely to have a greater

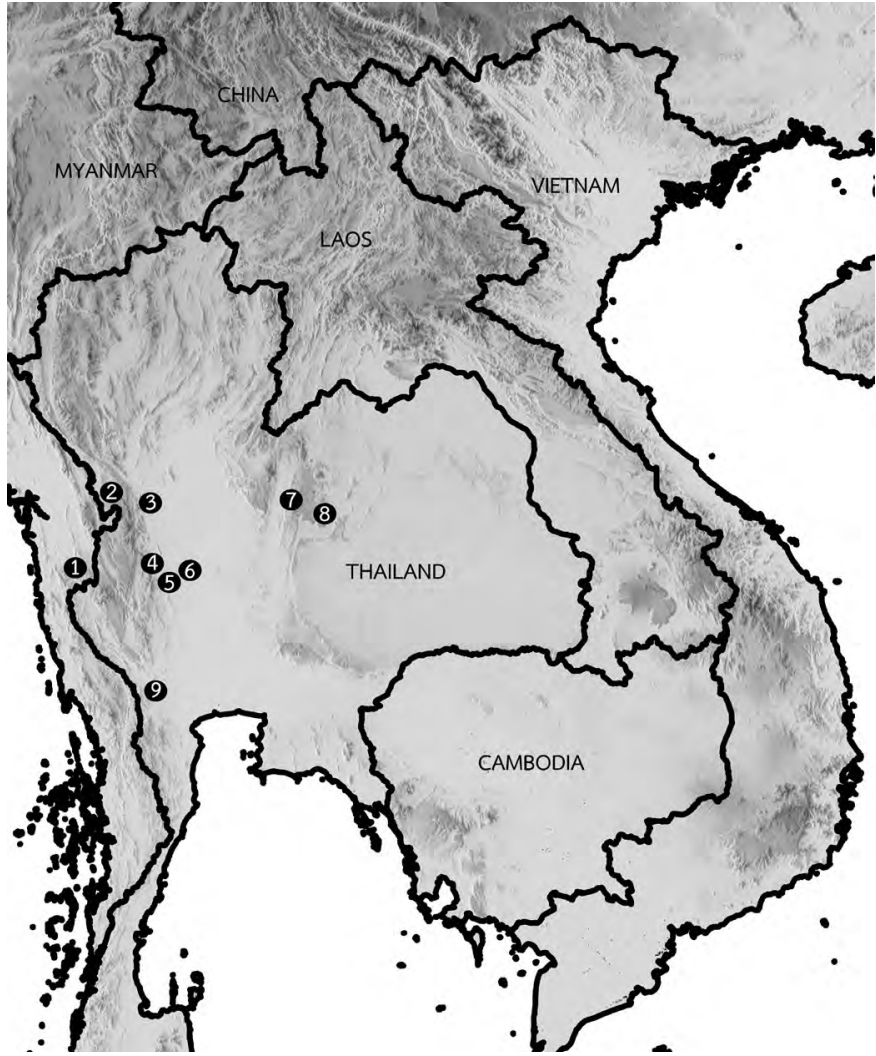

Figure 3. Known distribution of Isopachys borealis. Localities are: 1) Phadow, 150 km S of Moulmein, Myanmar. 2) Mae Sot (300 m elev.), 60 km west of Tak, Tak province, Thailand. 3) Taling Sung (140 m elev.), 95 km NW of M. Nakhon Sawan, Kamphaeng Phet province, Thailand. 4) Dong Noi, Uthai Thani province, Thailand. 5) Lan Sak ( 80 m elev.), 20 km W of Mueang. Uthai Thani, Uthai Thani province, Thailand. 6) Tap-Tan (80 m elev.), Uthai Thani province, Thailand. 7) Nam Len (270 m elev.), $30 \mathrm{~km}$ northeast of Phechabun, Phetchabun province, Thailand. 8) Nong Rua (250 m elev.), 45 km W of Khon Kaen, Khon Kaen province, Thailand. 9) Salak Phra Wildlife Sanctuary, Kanchanaburi province, Thailand.

number of voucher specimens housed in various collections (e.g., Lönnberg 1916; Taylor 1963; Lang and Böhme 1990; Kunya et al. 2011). However, the distribution of I. anguinoides is also limited similar to those of the three other Isopachys (known from Chumphon, Phetchaburi, Prachuap Khiri Khan, Surat Thani provinces; Chuaynkern and Chuaynkern 2012). Kamsook et al. (2006) referred to the limbless skink Isopachys sp. from Phu Khiew Wildlife Sanctuary (Chaiyaphum province, northeastern Thailand) but its voucher specimen was not cited. Phu Khiew Wildlife Sanctuary is located nearby locality 8 (Figure 3 ) ca. $70 \mathrm{~km}$ southwest of Nong Rua (=Nong Rua district, Khon Kaen province). The Isopachys sp. as referred to by Kamsook et al. (2006) is possibly I. borealis or I. roulei because its locality falls within the distribution range of $I$. borealis or possibly I. roulei and its highest latitude falls in area of Nakhon Ratchasima province which is bordered in the south by Chaiyaphum province (Kunya et al. 2011). Furthermore, three other congeners are known to reside along the coast of the Gulf of Thailand and also in the western part of the country.

Although the additional discovery of Isopachys borealis in Kanchanaburi province as reported in this work brings the total known locality of specimens to nine (Figure 3) - Phadow (150 km south of Moulmein, Myanmar), Mae Sot (6o km west of Tak, Tak province, 
Thailand), Taling Sung (M Nakhon Sawan, Kamphaeng Phet province, Thailand), Dong Noi (Uthai Thani province, Thailand), Lan Sak (2okmwest of Mueang Uthai Thani, Uthai Thaniprovince, Thailand), Tap-Tan (Uthai Thani province, Thailand), Nam Len (3o km northeast of Phechabun, Phetchabun province, Thailand), Nong Rua ( $45 \mathrm{~km}$ west of Khon Kaen, Khon Kaen province, Thailand) and Salak Phra Wildlife Sanctuary, Kanchanaburi province) — there are still insufficient voucher specimens for a conclusive understanding of the species' geographic distribution. This scarcity of voucher specimens might be due to the members of this group inhabiting underground habitats (Smith 1935, 1937; Taylor 1963; Heyer 1972; Lang and Böhme 1990; Das 2010). Moreover, the natural history of $I$. borealis is little known, and taxonomic workers have failed to find this skink in its natural habitat. This species' status has not yet been assessed for the IUCN Red List (IUCN 2013). For these reasons, I. borealis was assessed as Near Threatened in the Thailand Red Data (Nabhitabhata and Chanard 2005). Although the present work helps to fill a perceived distributional gap, our knowledge of $I$. borealis is still based only on morphology and a few distributional records. Therefore, further research on this species is needed before a more accurate assessment can be made.

We strongly believe that the geographical distribution of Isopachys borealis, and its congeners, are likely not fully known. Additional undiscovered populations probably exist in the gaps between the western, central and northeastern Thailand or populations may extend further to the north or south and southeast, and into neighboring parts of Laos and Myanmar. This lack of definitive knowledge exists even though the herpetofauna of the Indochinese region has been given considerable attention during the last decade. Several new species and additional records were published by various authors (e.g., Teynié et al. 2004; Stuart and Emmett 2006), and our knowledge of these animals grows rapidly with regularly published checklists (Chan-ard et al. 1999; Nabhitabhata 2000; Nabhitabhata et al. 2004; Nabhitabhata and Chan-ard 2005; Chuaynkern and Chuaynkern 2012). However, further fieldwork likely will reveal additional records of $I$. borealis.

\section{ACKNOWLEDGMENTS}

The authors would like thank our institutions for facilitating this work: Khon Kaen University, Khon Kaen province, Thailand, and Kasetsart University, Bangkok, Thailand. Our special thanks go to Nithina Kaewtongkum and Pechrkawin Nurngsomsri from the Department of Biology, Faculty of Science, Khon Kaen University, for assistance in drawing and preparing the illustration. We also thank Robert $\mathrm{H}$. Orr for reviewing and correcting an earlier manuscript. For permission, we would like to thank the Department of National Park, Wildlife and Plant Conservation (Collection permit No. 0907.4/5185; the issuing agency was the Department of National Park, Wildlife and Plant Conservation, Bangkok, Thailand).

\section{LITERATURE CITED}

Chan-ard, T., W. Grossmann, A. Gumprecht and K.-D. Schulz. 1999. Amphibians and Reptiles of Peninsular Malaysia and Thailand. An illustrated Checklist. Wuerselen: Bushmaster Publications. 240 pp.

Chuaynkern, Y. and C. Chuaynkern. 2012. Checklist of reptiles in Thailand. Journal of Wildlife in Thailand 19(1): 75-162 (in Thai with an English abstract).
Das, I. 2010. A Field Guide to the Reptiles of Thailand and South-East Asia. Bangkok: Asia Books. 376 pp.

Heyer, W.R. 1972. A new limbless skink (Reptilia: Scincidae) from Thailand with comments on the generic status of the limbless skinks of Southeast Asia. Fieldiana (Zoology) 58(10): 109-129.

IUCN. 2013. IUCN Red List of Threatened Species. Version 2013.2. Electronic database accessible at http://www.iucnredlist.org. Captured on 18 February 2014

Kamsook, M., K. Somsri and W. Puangsai. 2006. Amphibian and reptile diversity in Phu Khieo Wildlife Sanctuary, Chaiyaphum province; pp. 270-284, in: V. Baimai and R. Tantalakha (eds.). BRT 2006 Research Reports. Krabi: Chuan Printing Press Ltd. (in Thai with an English abstract).

Kunya, K., S. Kamolnorranath, T. Chan-ard, M. Cota and S. Makchai. 2011. Additional locality of an endemic legless skink, Isopachys roulei (Angel, 1920) (Squamata, Scincidae) from northeastern Thailand. The Thailand Natural History Museum Journal 5(1): 89-93.

Lang, M. and W. Böhme. 199o. Description and phylogenetic position of a new species of Isopachys from central Thailand and southern Burma/Myanmar (Squamata, Scincidae). Bulletin de l'Institut Royal des Sciences Naturelles de Belgigue, Biologie 60: 231-240.

Lönnberg, E. 1916. Zoological results of the Swedish Zoological Expeditions to Siam 1911-1912 and 1914. 2. Lizards. Kungl. Svenska. Vetenskapsakademiens Handlingar (Ny Följd) 55(4): 1-12 (http://biodiversitylibrary.org/page/41848608).

Nabhitabhata, J. 2000. Checklist of Amphibians and Reptiles in Thailand. Bangkok: Office of Environmental Policy and Planning. 77 pp.

Nabhitabhata, J. and T. Chan-ard. 2005. Thailand Red Data: Mammals, Reptiles and Amphibians. Bangkok: Office of Natural Resources and Environmental Policy and Planning. 234 pp.

Nabhitabhata, J., T. Chan-ard and Y. Chuaynkern. 2004. Checklist of Amphibians and Reptiles in Thailand. Bangkok: Office of Environmental Policy and Planning. $152 \mathrm{pp}$.

Smith, M.A. 1935. The fauna of British India, including Ceylon and Burma. Reptiles and Amphibia, Vol. II. Sauria. London: Taylor and Francis. $440 \mathrm{pp}$.

Smith, M.A. 1937. A review of the genus Lygosoma (Scincidae: Reptilia) and its allies. Records of the Indian Museum 39(3): 213-234.

Stuart, B.L. and D.A. Emmett. 2006. A collection of amphibians and reptiles from the Cardamom Mountains, southwestern Cambodia. Fieldiana, Zoology (New Series) 109: 1-27.

Tantipisanuh, N. and G.A. Gale. 2013. Representation of threatened vertebrates by a protected area system in Southeast Asia: the importance of non-forest habitats. The Raffles Bulletin of Zoology 61(1): 359-395 (http://lkcnhm.nus.edu.sg/nus/index. $\mathrm{php} / 62 / 19$-research/research-publications/past-volumes/74rbz-61-2-453-893-30-august-2014).

Taylor, E.H. 1963. The lizards of Thailand. The University of Kansas Science Bulletin 44(14): 687-1077 (http://biodiversitylibrary.org/ page/3280261).

Teynié, A., P. David, A. Ohler and K. Luanglath, K. 2004. Notes on a collection of amphibians and reptiles from southern Laos, with a discussion of the occurrence of Indo-Malayan species. Hamadryad 29: $33-62$.

Uetz, P. and J. Hošek (eds.) 2014. The Reptile Database. Electronic database accessible at http://www.reptile-database.org. Captured on 17 February 2014.

Authors' contribution statement: WC collected the specimen and $\mathrm{YC}, \mathrm{PD}$, and $\mathrm{CC}$ wrote the text.
Received: May 2014
Accepted: July 2014
Editorial responsibility: Perry Wood 